\title{
Corrigendum to "Exercise Training Restores Cardiac MicroRNA-1 and MicroRNA-29c to Nonpathological Levels in Obese Rats"
}

\author{
André C. Silveira $\left(D,{ }^{1}\right.$ Tiago Fernandes, ${ }^{1}$ Úrsula P. R. Soci, ${ }^{1}$ João L. P. Gomes ${ }^{D}{ }^{1}$ \\ Diego L. Barretti, ${ }^{1}$ Glória G. F. Mota, ${ }^{1}$ Carlos Eduardo Negrão, ${ }^{1,2}$ \\ and Edilamar M. Oliveira $(\mathbb{D})^{1}$ \\ ${ }^{1}$ Laboratory of the Biochemistry and Molecular Biology of Exercise, School of Physical Education and Sport, University of Sao Paulo, \\ Sao Paulo, SP, Brazil \\ ${ }^{2}$ Heart Institute (InCor), Medical School, University of São Paulo, São Paulo, SP, Brazil \\ Correspondence should be addressed to Edilamar M. Oliveira; edilamar@usp.br \\ Received 4 December 2017; Accepted 12 December 2017; Published 25 February 2018 \\ Copyright (c) 2018 André C. Silveira et al. This is an open access article distributed under the Creative Commons Attribution \\ License, which permits unrestricted use, distribution, and reproduction in any medium, provided the original work is properly cited.
}

In the article titled "Exercise Training Restores Cardiac MicroRNA-1 and MicroRNA-29c to Nonpathological Levels in Obese Rats" [1], an acknowledgment should be added as follows.

This study was supported by Fundação de Amparo à Pesquisa do Estado de São Paulo (FAPESP-2009/183703 and 2010/50048-1); Programa de Inovação Tecnológica/ CEPID (Centros de Pesquisa, Inovação e Difusão) (2013/ 07607-8); USP/PRP: Núcleo de Apoio à Pesquisa com microRNAs-NAP and Pro-Infra; Conselho Nacional de Desenvolvimento Científico e Tecnológico-CNPq (no. 308267/2013-3); Programa PIBIC; and the Brazilian Federal Agency for Support and Evaluation of Graduate Education (CAPES-PROEX).

\section{References}

[1] A. C. Silveira, T. Fernandes, Ú. P. R. Soci et al., "Exercise training restores cardiac MicroRNA-1 and MicroRNA-29c to nonpathological levels in obese rats," Oxidative Medicine and Cellular Longevity, vol. 2017, Article ID 1549014, 12 pages, 2017. 


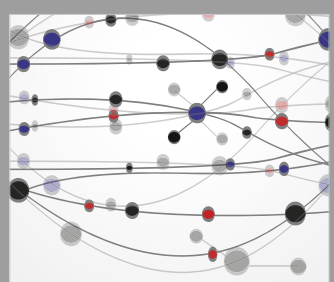

The Scientific World Journal
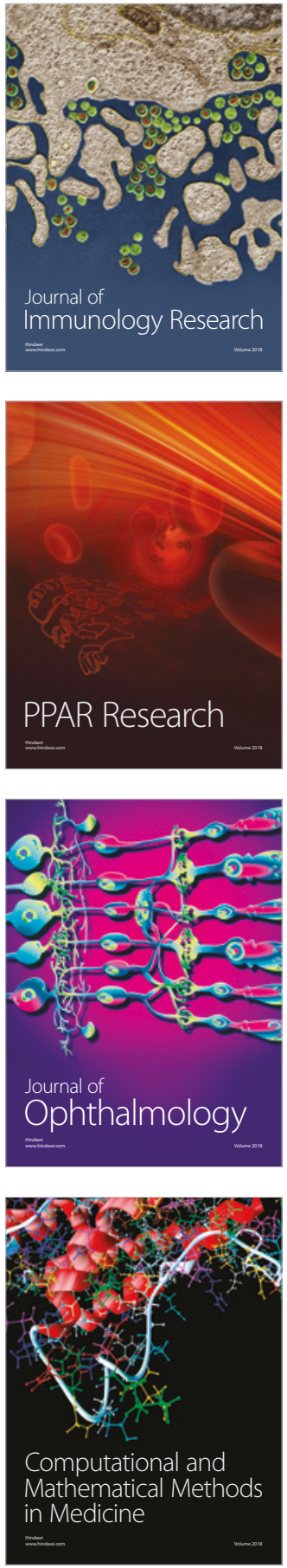

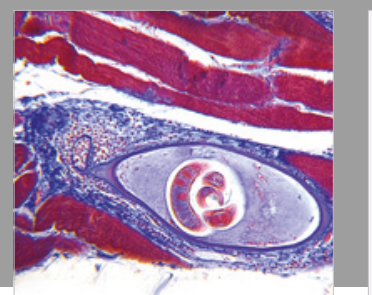

Gastroenterology Research and Practice

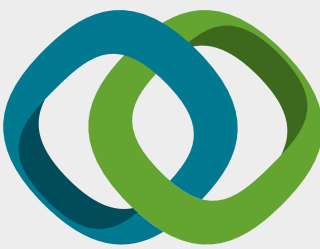

\section{Hindawi}

Submit your manuscripts at

www.hindawi.com
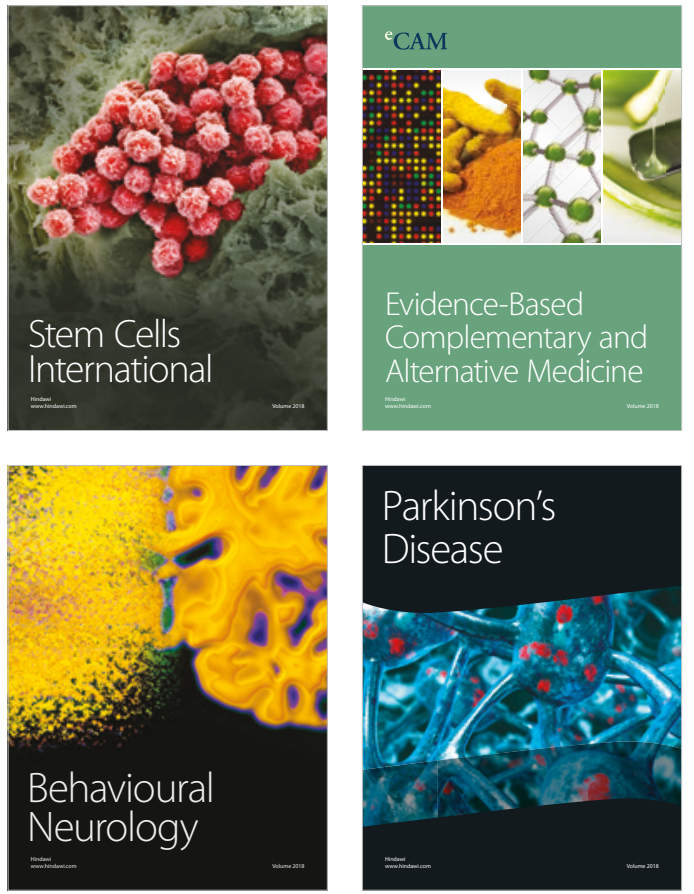

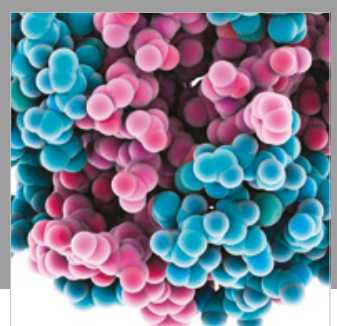

ournal of

Diabetes Research

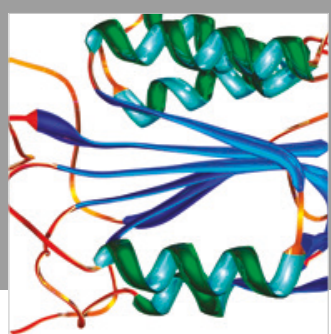

Disease Markers
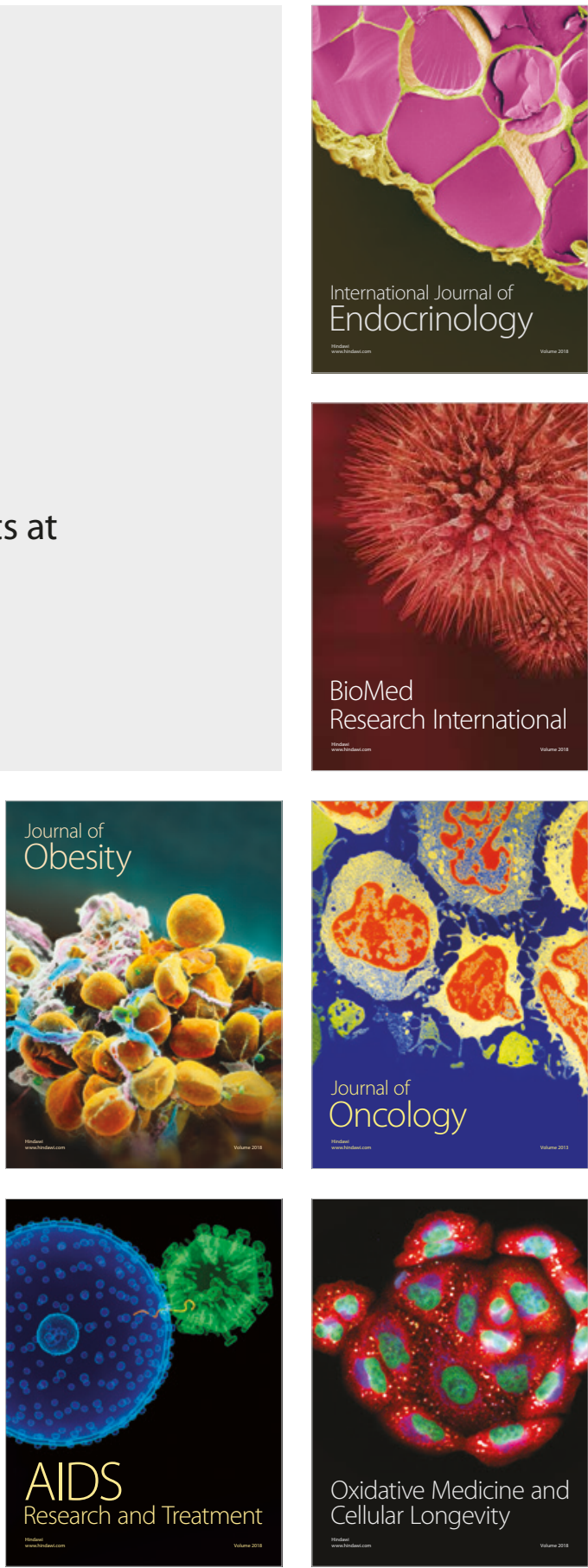